\title{
Effects of adrenal demedullation and adrenalectomy on an active avoidance response of rats
}

\author{
M. TERESA A. SILVA* \\ Departamento de Psicobiologia, Escola Paulista de Medicina, Rua Botucatu, 862,04023 São Paulo, Brazil
}

\begin{abstract}
Extinction of a one-way avoidance response was studied in adrenalectomized, adrenal demedullated, and operated control albino male rats. The response was acquired under $0.3-, 0.6-$, or $1.0-\mathrm{mA}$ shock stimulation. In general, adrenalectomized rats were slower to extinguish than both demedullated and operated control animals. In the most stressful acquisition condition $(1.0 \mathrm{~mA})$, demedullated animals were as resistant to extinction as adrenalectomized animals. Relationship of these results to the possible involvement of the pituitary-adrenal system in fear-motivated behavior was discussed.
\end{abstract}

Weiss, McEwen, Silva, and Kalkut (1970) have shown that extinction of an active avoidance response is prolonged in adrenalectomized rats. The effect was attributed to alterations in the pituitary-adrenal system resulting from adrenal extirpation. Thus, the increased adrenocorticotrophic hormone (ACTH) levels of adrenalectomized animals (Cox, Hodges, \& Vernikos, 1958; Hodges \& Jones, 1964) would have led to increased excitability in the avoidance situation, and their minimal corticosteroid secretion would not have been sufficient to exert an inhibitory action on fear responding. Epinephrine deficiency due to lack of the adrenal medulla was not considered to be a critical factor in the results obtained, since from experiments like Kamano's (1968), one could infer that lack of the amine would have influenced behavior in the opposite direction from that observed in adrenalectomized animals.

However, behavioral effects of epinephrine are still a controversial matter. Exogenous administration of the hormone or adrenal demedullation have yielded evidence pointing to a facilitatory role of epinephrine in fear responding (Latané \& Schachter, 1962; Singer, 1963; Kamano, 1968), but results are often discreet (Levine \& Soliday, 1962) or disputable (Stewart \& Brookshire, 1967, 1968; Moran, Ahmad, \& Meagher, 1970).

In the present experiments, adrenal demedullated, adrenalectomized, and operated control rats were studied in conditions closely resembling those of Weiss et al (1970), in an attempt to verify whether epinephrine deficiency would contribute to the increased resistance to active avoidance extinction shown by adrenalectomized rats.

\section{METHOD}

Ss used were 149 3-month-old male Wistar rats weighing $200-250 \mathrm{~g}$ at the start of the experiment. Each experimental condition comprised one adrenalectomized (ADX), one

*Supported by Fundação de Amparo à Pesquisa do Estado de Sào Paulo (FAPESP) and Conselho Nacional de Pesquisas (CNPq). The author is thankful to Candida Macedo Soares for help in running the experiments. adrenaldemedullated (DEM), and one operated control (SHAM) group of rats, living 5 per cage with food and water ad lib; adrenalectomized rats were also provided with $1.8 \% \mathrm{NaCl}$ solution. Adrenalectomies were performed 7 days before the experiments, time needed to secure elevation of ACTH levels above normal (Cox, Hodges, \& Vernikos, 1958; Hodges \& Jones, 1964), whereas medullectomies were performed 30 days before the experiments, in order to allow for cortical regeneration. Both operations were made according to Farris and Griffith (1949). Control operations were performed in phase with the other surgery, that is, 7 or 30 days before the experiments. Histological examination of the adrenal glands after medullectomy had been performed before in our laboratory (Silva, 1972). They showed that, with the technique used, the adrenal medulla is thoroughly expelled, together with the reticular layer and part of the fasciculata layer of the cortex. In order to assess the effectiveness of adrenalectomies and the degree of cortical regeneration after medullectomies, fluorometric determination of poststress plasma corticosterone levels (Guillemin, Clayton, Smith, \& Lipscomb, 1958) was performed at the end of the experiments.

Ss were run in a shuttlebox apparatus $(60 \times 30 \times 25 \mathrm{~cm})$ in which a black compartment was connected to a white one through a moveable $8 \times 9 \mathrm{~cm}$ door. The black compartment had a grid floor connected to a constant ac shock generator, while the white compartment floor was covered with cardboard.

Groups of ADX, DEM, and SHAM rats were assigned to three experimental conditions, corresponding to the shock intensity employed in conditioning: $0.3,0.6$, or $1.0 \mathrm{~mA}$. In the first experimental session, each $\mathrm{S}$ was habituated to the apparatus for $15 \mathrm{~min}$, after which acquisition trials began. Each trial followed this sequence: the $\mathrm{S}$ was confined for $30 \mathrm{sec}$ in the black compartment; then the door was opened, and $10 \mathrm{sec}$ later shock was delivered through the grid bars until $S$ crossed to the white side. If $\mathrm{S}$ crossed within $10 \mathrm{sec}$, shock was avoided. The animal remained in the white compartment for another $30 \mathrm{sec}$, and was then transferred back to the shock compartment for the next trial. The acquisition criterion was five consecutive avoidance responses. Once it was reached, the extinction phase began. Extinction trials were carried out in the same way as acquisition trials, except that no shock was delivered. If the animal did not cross within $10 \mathrm{sec}$, the door was closed and the animal was left in the black compartment for $30 \mathrm{sec}$ before starting another trial. After five such failures to respond, the session was terminated. The second experimental session was conducted one week later. In the first trial, a single shock was given of the same intensity used in acquisition. Following the shock, extinction trials were again run in the same manner as in the first session. Movements during the first experimental session were registered using a 4-point rating scale (Weiss, Krieckhaus, \& Conte, 1968).

Data were treated by analysis of variance. Where means are 
Table 1

Plasma Corticosterone Concentration After Stress (Mean \pm SE) for ADX, DEM, and SHAM Groups in the Three Acquisition Conditions (Number of Subjects in Each Group Shown in Parentheses)

\begin{tabular}{|c|c|c|c|c|c|c|}
\hline \multirow{3}{*}{$\frac{\text { Group }}{\text { SHAM }}$} & \multicolumn{6}{|c|}{ Micrograms $/ 100 \mathrm{ml}$ Corticosterone } \\
\hline & \multicolumn{2}{|c|}{$0.3 \mathrm{~mA}$} & \multicolumn{2}{|c|}{$0.6 \mathrm{~mA}$} & \multicolumn{2}{|c|}{$1.0 \mathrm{~mA}$} \\
\hline & $16.6 \pm 1.5$ & (15) & $16.5 \pm 2.4$ & (18) & $19.5 \pm 2.6$ & (15) \\
\hline $\mathrm{ADX}$ & $2.7 \pm 0.5^{*}$ & $(19)^{* *}$ & $1.9 \pm 0.2^{*}$ & (18) & $0.9 \pm 0.5 *$ & $(10) \dagger$ \\
\hline DEM & $16.3 \pm 1.7$ & (15) & $16.1 \pm 1.3$ & (18) & $14.2 \pm 2.2$ & (15) \\
\hline
\end{tabular}

${ }^{*} p<.001$ by SHAM and DEM (t test) ${ }^{* *} N=20$ during first experimental session $\quad \dagger N=15$ during first experimental session

shown, $F$ and $t$ tests were used; where medians are employed, the Kruskal-Wallis analysis of variance and the $U$ test were used. The number of animals in each group is shown in Table 1.

\section{RESULTS}

Acquisition data are presented in Fig. 1. Analysis of variance showed that, with one exception, within each shock intensity condition ADX, DEM, and SHAM groups were not significantly different in mean number of shocks taken or in mean total number of trials needed before reaching the acquisition criterion. Acquisition was generally slowest in the $0.3-\mathrm{mA}$ condition, though among ADX groups, the difference was not significant.

Performance during extinction disclosed marked differences among groups. Figure 2 shows the median number of responses during extinction on the first and second experimental session. In the most intense shock condition employed $(1.0 \mathrm{~mA})$, the two hormone deficient groups made significantly more responses during the first extinction session than the SHAM group $(p<0.001)$. In the second extinction session in this condition, however, only Ss in the ADX group exhibited significantly greater resistance to extinction than those in the SHAM group $(p<0.02)$; DEM group scores approached SHAM group results. Similarly, in the intermediate shock condition $(0.6 \mathrm{~mA})$ rats in the ADX group extinguished slower than those in the SHAM $(p<0.05)$ and DEM $(p<0.02)$ groups, in the first extinction session; in the second one, $\mathrm{ADX}$ animals were again slower than SHAM controls $(p<0.05)$. Finally, in the lowest shock intensity condition $(0.3 \mathrm{~mA})$, the only significant effect appeared in the first session and was due to a slight acceleration in extinction observed in the DEM group in relation to the ADX $(p<0.05)$ and SHAM $(\mathrm{p}<0.1, \mathrm{~ns})$ groups.

Mean number of fecal boluses eliminated during the first and second experimental sessions is also presented in Fig. 2. ADX groups, in general, showed increased defecation in relation to both DEM and SHAM groups in any shock condition, the differences being significant in the first experimental session for the $0.3-$ and $0.6-\mathrm{mA}$ conditions. It is clear from Fig. 2 that defecation increased as a function of stimulus intensity in the three surgical groups. Movement scores, measured during the first session, were not significantly different among groups in any condition. Table 1 shows that cortical secretion was deficient in ADX groups but similar to normal in DEM groups.

\section{DISCUSSION}

As mentioned before, the adrenal demedullation technique employed in this experiment produces complete removal of medullary tissue. Studies of urinary excretion of epinephrine after medullectomy indicate that, under normal conditions, the amine is derived mainly from medullary chromaffin cells (Vogt, 1952; Crawford \& Law, 1958; Biscardi, Carpi, \& Orsingher, 1964; von Euler, 1967). Moreover, the enzyme that converts norepinephrine to epinephrine, phenylethanolamine-N-methyl transferase, is highly localized to the adrenal medulla (Wurtman, 1965). Thus,
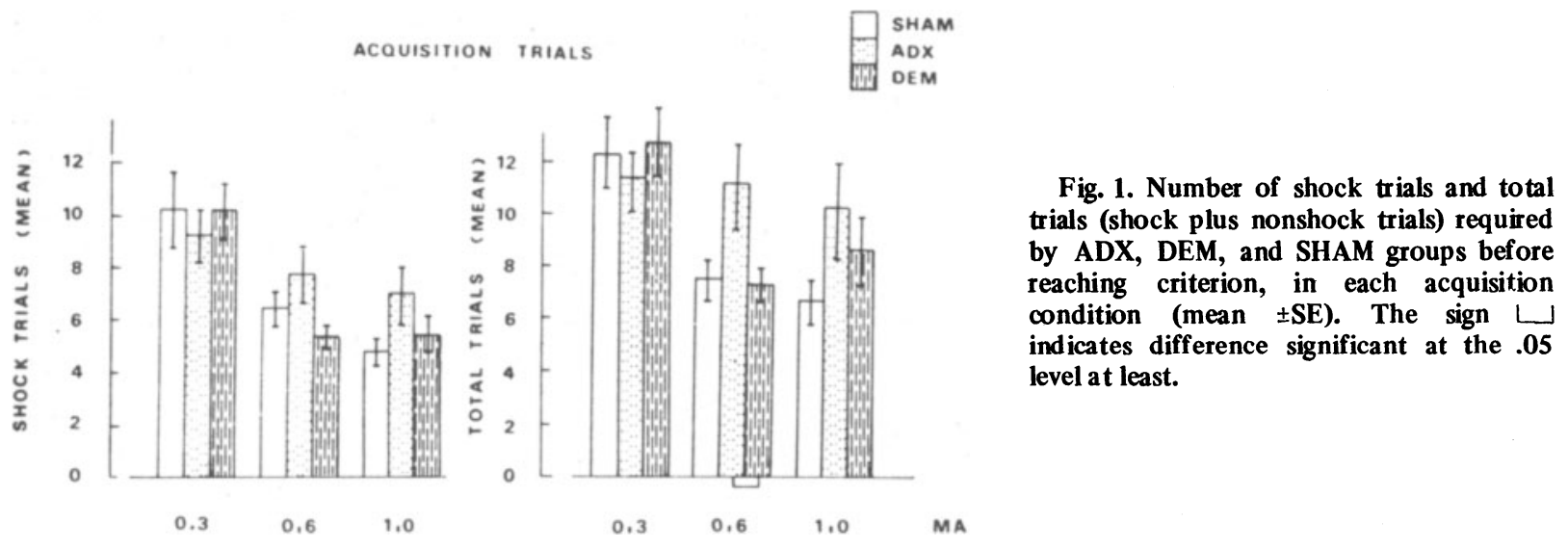

Fig. 1. Number of shock trials and total trials (shock plus nonshock trials) required by ADX, DEM, and SHAM groups before reaching criterion, in each acquisition condition (mean $\pm S E$ ). The sign $L$ indicates difference significant at the .05 level at least. 
Fig. 2. Number of responses during extinction (median) and fecal boluses eliminated (mean \pm SE) on the first and second experimental session, for ADX, DEM, and SHAM groups in each acquisition condition. The sign $L\rfloor$ indicates difference significant at the .05 level at least.
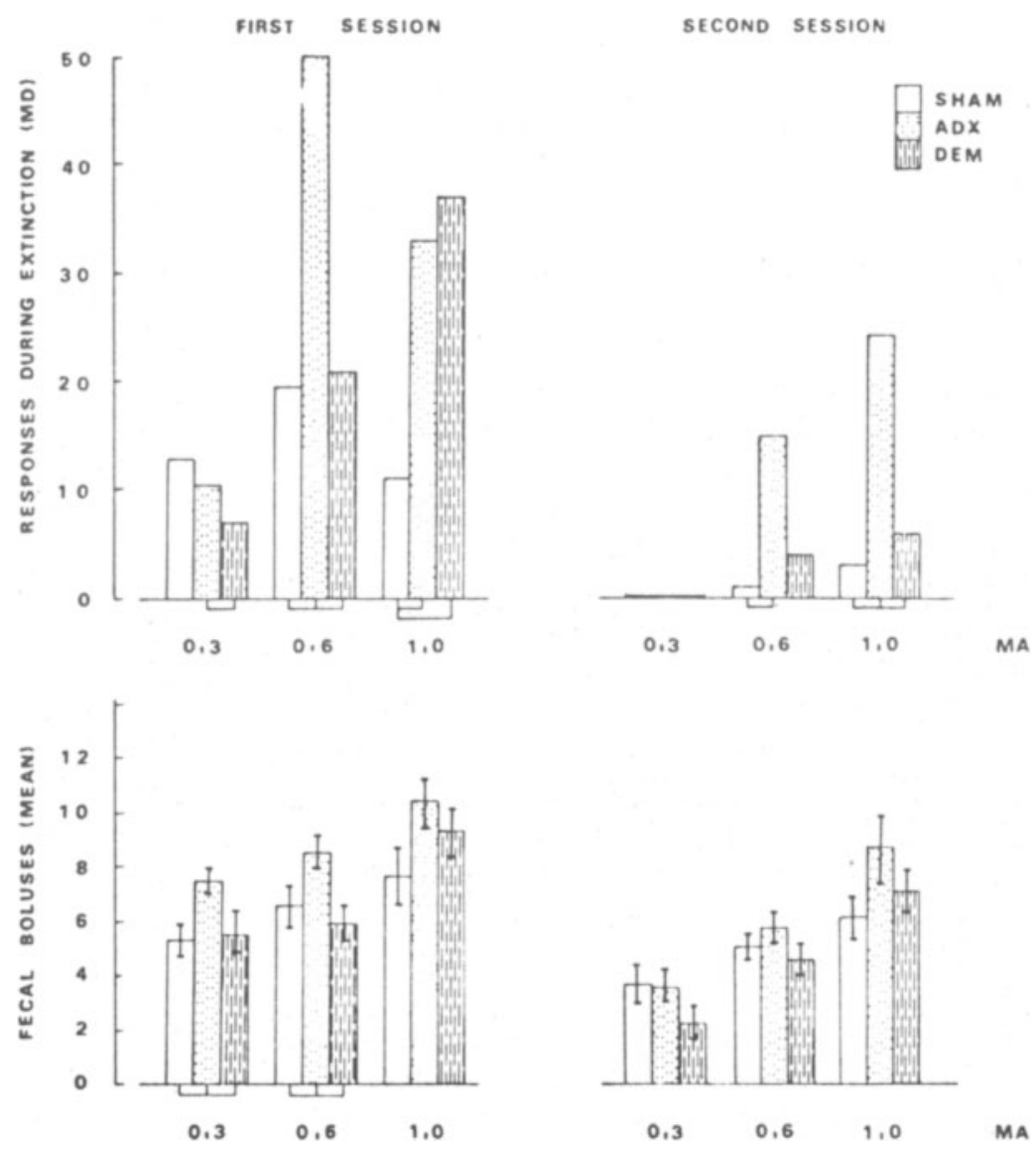

one can safely assume that removal of the adrenal medulla produced a drastic reduction of circulating epinephrine.

In spite of the advisability of running demedullated Ss as adrenalectomy controls (Di Giusto, Cairncross, \& King, 1971), it appears that absence of the medulla and consequent epinephrine deficiency did not play a major role in the behavior exhibited by adrenalectomized rats. In most of the situations analyzed, adrenalectomized animals were more resistant to extinction of an active avoidance response than both adrenaldemedullated and operated control rats. They also showed increased defecation as compared to those two groups. Similar results have been reported for extinction of a passive avoidance response in adrenalectomized and demedullated rats (Silva, 1973). Thus, the view remains unchallenged that supranormal fear responding after adrenalectomy is attributable to elevated ACTH levels coupled to diminished corticosteroid response (Weiss et al, 1969).

In one sole case, the extinction rates of demedullated and adrenalectomized Ss were comparable, and that was in the first extinction session under the strongest shock intensity condition (1.0 mA). This relevant exception did not occur on the second extinction session, when a single shock was applied, suggesting that it could be a function of quantit suffered by the ar under conditions demedullated animals were hypersensitive to the characteristic stress-induced sympathetic and parasympathetic activation. However, the data can be viewed in another way. Figure 2 shows that the median number of responses of demedullated groups in the first extinction session tended to increase as a function of shock intensity. On the other hand, the picture for adrenalectomized and operated control groups resembles rather an inverted U-shaped function. Therefore, it is active responses in adrenalectomized and control operated Ss was absent in demedullated animals. Their peculiar behavior in the $1.0 \mathrm{~mA}$ condition could then be a reflection of decreased susceptibility to "freezing" effects or to the interference of arousal in behavioral efficiency (Manto, 1967; Frankenhaeuser, 1971).

Although adrenal demedullation effects were not striking in the present experiments, it should be noted that epinephrine rise had been correlated with situations defined by ambiguity, novelty, and unpredictability of stimulation (Mason, Mangan, Brady, Conrad, \& Rioch, 1961; Mandler, 1967; Frankenhaeuser \& Rissler, 1970), so that the tasks used here may not have been the most plausible to assume that the factor competing with 
suitable for detection of behavioral consequences of epinephrine deficiency.

A final point to be made concerns the influence of corticosteroids on sensory detection and perceptual ability (Henkin, 1970). A control for this factor should be included in future experiments using adrenalectomized Ss, so that results can not be open to an interpretation based on perception alterations.

\section{REFERENCES}

Biscardi, A. M., Carpi, A., \& Orsingher, O. A. Urinary excretion of catechol amines in the rat after their liberation by reserpine or dexamphetamine. British Journal of Pharmacology, 1964, 23, 529-539.

Cox, G. S., Hodges, J. R., \& Vernikos, J. The effect of adrenalectomy on the circulating level of adrenocorticotrophic hormone in the rat. Journal of Endocrinology, 1958, 17, 177-181.

Crawford, T. B. B., \& Law, W. The urinary excretion of adrenaline and noradrenaline by rats under various experimental conditions. British Journal of Pharmacology, $1958,13,35-43$.

Di Giusto, E. L., Cairncross, K., \& King, M. G. Hormonal influences on fear-motivated responses. Psychological Bulletin, $1971,75,432-444$

Farris, E. J., \& Griffith, J. Q., Jr. The rat in laboratory investigation. Philadelphia: Lippincott, 1949.

Frankenhaeuser, M. Behavior and circulating catecholamines. Brain Research, 1971, 31, 241-262.

Frankenhaeuser, M., \& Rissler, A. Effects of punishment on catecholamine release and efficiency of performance. Psychopharmacologia (Berlin), 1970, 17, 378-390.

Guillemin, R., Clayton, G. W., Smith, J. D., \& Lipscomb, H. S. Me a surement of free corticosteroids in rat plasma: Physiological validation of a method. Endocrinology, 1958, $63,349-358$.

Henkin, R. I. The effects of corticosteroids and ACTH on sensory systems. Progress in Brain Research, 1970, 32 270-294.

Hodges, J. R., \& Jones, M. T. Changes in pituitary corticotrophic function in the adrenalectomized rat. Journal of Physiology, 1964, 173, 190-200.

Kamano, D. K. Enhancement of learned fear with epinephrine. Psychonomic Science, 1968, 12, 331.

Latané, B., \& Schachter, S. Adrenalin and avoidance learning. Journal of Comparative \& Physiological Psychology, 1962, 55 , 369-372.

Levine, S., \& Soliday, S. An effect of adrenal demedullation on the acquisition of a conditioned avoidance response. Journal of Comparative \& Physiological Psychology, 1962, 55, 214-216.

Mandler, G. The conditions for emotional behavior. In D. C. Glass, (Ed.), Neurophysiology and emotion. New York: Rockefeller University Press, 1967.

Manto, P. G. Blockade of epinephrine-induced decrement in activity by scopolamine. Psychonomic Science, 1967, 7, 203-204.

Mason, J. W., Mangan, G., Brady, J. V., Conrad, D., \& Rioch, D. $M$. Concurrent plasma epinephrine, norepinephrine and 17-hydroxy corticosteroid levels during conditioned emotional disturbances in monkeys. Psychosomatic Medicine, 1961, 23, 344-353.

Moran, G., Ahmad, S. S., \& Meagher, R. B. Adrenalin and avoidance learning: Partial replications, Journal of Experimental Research in Personality, 1970, 4, 84-89.

Silva, M. T. A. Papel do hormônio adrenocorticotrófico (ACTH) e de hormônios adrenais no comportamento de esquiva de ratos. Unpublished doctoral dissertation, Instituto de Psicologia, Universidade de São Paulo, 1972.

Silva, M. T. A. Extinction of a passive avoidance response in adrenalectomized and demedullated rats. Behavioral Biology, $1973,9,553-562$.

Singer, J. E. Sympathetic activation, drugs, and fear. Journal of Comparative \& Physiological Psychology, 1963, 56, 612-615.

Stewart, C. N., \& Brookshire, K. H. Shuttle box avoidance learning and epinephrine. Psychonomic Science, 1967, 9, 419-420.

Stewart, C. N., \& Brookshire, K. H. Effect of epinephrine on acquisition of conditioned fear. Physiology \& Behavior, 1968 3, 601-604.

Vogt, M. Plasma adrenaline and release of ACTH in normal and demedullated rats. Journal of Physiology, 1952, 118, 588-594.

von Euler, U. S. Adrenal medullary secretion and its neural control. In L. Martini and W. F. Ganong (Eds.), Neuroendocrinology. New York: Academic Press, 1967.

Weiss, J., Krieckhaus, E. E., \& Conte, R. Effects of fear conditioning on subsequent avoidance behavior and movement. Journal of Comparative \& Physiological Psychology, 1968, 65, 413-421.

Weiss, J. M., McEwen, B. S., Silva, M. T. A., \& Kalkut, M. F Pituitary-adrenal influences on fear responding. Science; 1969, 163, 197-199.

Weiss, J. M., McEwen, B. S., Silva, M. T. A., \& Kalkut, M. F. Pituitary-adrenal alterations and fear responding. American Journal of Physiology, 1970, 218, 864-868.

Wurtman, R. J. Catecholamines. New England Journal of Medicine, 1965, 273, 637-646.

(Received for publication December 18, 1973; revision received February 7,1974 accepted February 19, 1974.) 